\title{
La buena administración como institución jurídica
}

\author{
José Luis Meilán Gil \\ Catedrático de Derecho Administrativo \\ Miembro de la Real Academia Gallega de Jurisprudencia y Legislación \\ Ex Consejero de Estado
}

\begin{abstract}
SUMARIO: I. PLANTEAMIENTO. II. LA IDEA DE BUEN GOBIERNO. 1. La justificación del poder público. 2. Identificación entre gobierno y administración. 3. Diferenciación entre buen gobierno y administración. III. LA BUENA ADMINISTRACIÓN. 1. Administración Pública y administración privada: excurso. 2. La "buena administración", como principio jurídico. 3. La "buena administración" como derecho fundamental. 4. La insuficiencia de la perspectiva garantista de la buena administración. 5. Eficacia jurídica de principios programáticos. 6. El Defensor del Pueblo y la mala administración. 7. Actualidad de la transparencia para la buena administración. IV. EPÍLOGO SOBRE ÉTICA Y ADMINISTRACIÓN
\end{abstract}

\section{RESUMEN:}

El presente estudio supone una reflexión actual sobre el principio de "buena administración". Se distingue del concepto de "buen gobierno", que tiene un alto componente político, en la medida en que la "buena administración" se configura alrededor de un contenido jurídico, que debe ser rellenado (y así lo ha sido trabajosamente) por la jurisprudencia y las leyes. Se analizan las huellas que diferentes elementos asociados a la buena administración han ido dejando en la jurisprudencia española y comunitaria (eficiencia, eficacia, motivación, buena actuación contractual o de selección funcionarial, sometimiento al Derecho, etc.). También la correcta organización administrativa es parte no desdeñable del concepto, aunque el Derecho administrativo le ha prestado escasa atención (centrado como ha estado, desde su configuración inicial, en el estudio de las patologías, esto es, del control contencioso-administrativo). En el Tratado de Lisboa ha quedado consagrado en uno de los derechos de la Carta de Derechos fundamentales de la UE, de la que se sigue su acuñación como "derecho fundamental" 
en nuestro ordenamiento, con consecuencias importantes a todos los efectos. También se analiza su relación con la transparencia en la Ley 19/2013, de Transparencia administrativa. Aunque el principio de buena administración no debe tener un sesgo moralizante, al estar la Administración compuesta por funcionarios, es deseable que éstos tiendan a la virtud (Sto. Tomás de Aquino), lo que excede, paradójicamente, de lo puramente jurídico.

\section{PALABRAS CLAVE:}

Buena administración; buen gobierno; ética y Administración

\section{ABSTRACT}

This study is a nowadays reflection on the principle of "good administration". It differs from the concept of "good governance", which has a high political component, to the extent that "good administration " is set around a legal content, which must be filled out (and it has been laboriously) by the case-law and Parliament. We analyze the footprints that different elements associated with good administration have been leaving in Spanish and EU jurisprudence (efficiency, effectiveness, motivation, good contractual performance or good civil service selection, rile of law, and so on... ). Also the sound administrative organization is non-negligible part of the concept, although the Administrative Law has paid little attention to it (focused, from its initial configuration, in the study of administrative "diseases", that is, the judicial control of the Administration). In the Treaty of Lisbon the right to a good administration has been recognized as one of the rights of the Charter of Fundamental Rights of the EU, with important consequences for all purposes. We also discuss his relationship with transparency as recognized in Spanish Act 19/2013, on Administrative Transparency. Although the principle of good administration should not have a moralistic bias, being composed the Administration by officials, it is desirable that they tend to virtue (St. Thomas Aquino), which exceeds paradoxically, the purely legal.

\section{KEY WORDS:}

Good administration; good governance; ethics and Administration

\section{PLANTEAMIENTO}

Se habla afortunadamente con frecuencia de la "buena administración". La expresión se ha introducido al máximo nivel del ordenamiento jurídico de la Unión Europea al figurar en la Carta europea de derechos fundamentales elevada al rango de tratado por el de Lisboa, figura, al menos como principio en ordenamientos jurídicos de los Estados miembros, y es citada en los fundamentos jurídicos de sentencias de tribunales ante los cuales puede ser invocada. No es so- 
lo una laudable preocupación doctrinal, ni un principio no exento de alegoría que trate de "dotar de alma a la Administración" ni, por tanto, un asunto que resida completamente extra muros del Derecho².

Es una obviedad sostener que en este tema hay implicaciones varias: de carácter sociológico, económico, político, ético, además del jurídico. Sucede también, sin que sea ahora cuestión de medir en qué proporciones, con el propio Derecho. Desde siempre lo he considerado como un fenómeno cultural, tomando la expresión en un sentido amplio. No se entienden de un modo cabal sus categorías sin tener en cuenta el contexto, incluida la historia; pero al construirlas y explicarlas no deberían mezclarse las diferentes perspectivas.

La "buena administración" puede ser expuesta utilizando indiscriminadamente todas esas perspectivas y, es posible que con ello se preste un gran servicio a la sociedad, pero no tanto al Derecho administrativo que tiene sus propias reglas y ámbito como ciencia. Sucede en este caso como con otros asuntos de gran actualidad como la corrupción. Por ello aquí se pregunta qué es o puede suponer la "buena administración" para el Derecho administrativo. Desde el Derecho no se asegura aquella en su integridad. La tarea de administrar se lleva a cabo por personas. Ni siquiera la tipificación de delitos y las correspondientes penas, ni de las infracciones y sanciones bastan, aunque puedan ayudar, a que los comportamientos correspondan al arquetipo de la "buena administración"; ni se asegura plenamente con el cumplimiento de lo establecido en el ordenamiento jurídico, trátese de preceptos o principios. La "buena cara" que pone un funcionario en su atención al ciudadano forma parte de la "buena administración", y tendrá su raíz en convicciones de educación o de ética que, se corresponden con el carácter de servidor público que, por otra parte, tiene su anclaje en la Constitución y en las leyes.

Se pretende, por tanto, abordar la "buena administración" desde la perspectiva del Derecho administrativo. Qué sentido tiene; cuál es su ámbito; qué consecuencias se derivan de su reconocimiento jurídico. Esa inserción en el Derecho

${ }^{1}$ J. TORNOS MAS, "El principio de la buena administración o el intento de dotar de alma a la Administración", Derechos fundamentales y otros estudios en homenaje al prof. Dr. Lorenzo Martín Retortillo, vol. I, Gobierno de Aragón, Cortes de Aragón, 2008, pp. 829 y ss.

${ }^{2}$ A su exposición, análisis y divulgación se ha dedicado con particular empeño el profesor J. RODRÍGUEZ-ARANA MUÑOZ, expresión de un autocalificado "pensamiento abierto, plural, dinámico y complementario" del que pueden citarse El Buen Gobierno y la Buena Administración de Instituciones Públicas, Thomson-Aranzadi, Cizur Menor, 2006 y Dereito fundamental â Boa Administraçao Pública, Forum, Belo Horizonte, 2012. 
proporciona una indudable garantía para que sea efectiva, más allá de proclamas y buenos deseos. Por seguir con el ejemplo de la corrupción, en el ámbito contractual de la Administración el Derecho puede combatirla regulando de una manera adecuada el iter que conduce hasta la selección del contratista y la adjudicación del contrato y, en favor de los mismos principios de igualdad, no discriminación y transparencia, impidiendo la prerrogativa de la Administración para la modificación del contrato ${ }^{3}$.

Dentro del ámbito de la "buena administración" en la Unión Europea lo decisivo para reconocer el derecho de los interesados a tener acceso a los documentos que posean la Comisión y el Consejo, antes de elevarlo al nivel de fundamental, no fue un Código de buena conducta ${ }^{4}$, sino la Decisión adoptada posteriormente ${ }^{5}$. La intención moralizadora de obligar a resolver expresamente, por ejemplo, resulta insuficiente desde una buena administración; debería generar, cuando menos, responsabilidad del funcionario. ${ }^{6}$ Todo ayuda, pero convertir la "buena administración", con lo que ello comporta, en un derecho colabora a que sea efectiva.

El propio enunciado de la "buena administración" proporciona un cierto equívoco, según que se exprese ortográficamente con minúsculas o con mayúsculas, que remite a la propia concepción del Derecho administrativo, dentro de lo que puede considerarse Derecho del Estado, al que pertenece también el Derecho constitucional. No parece necesario insistir en que el Derecho administrativo ha de hundir sus raíces en la Constitución, lo que me ha permitido hablar tempranamente de un Derecho administrativo constitucional, no solo como "Derecho constitucional concretizado", sino también por su virtud constitucionalizante $^{7}$; pero quizá no sea superfluo aludir a que la "buena administración" se

${ }^{3}$ Cfr. J.L.MEILÁN GIL, "Las prerrogativas de la Administración en los contratos administrativos: propuesta de revisión", RAP, 191, 2013.

${ }^{4}$ Sobre el soft law que preparó el acuerdo de Niza cfr. B. TOMÁS MALLÉN, El derecho fundamental a una buena administración, INAP, Madrid, 2004, pp. 89 y ss. El Código de buena conducta administrativa de 2001, del Defensor del Pueblo europeo tenía como objetivo "concretar en la práctica lo que significa el derecho a una buena administración establecido en la Carta".

${ }^{5}$ Cfr. STJE 2007/730 de 27 de noviembre, asunto Athanasios Pitsionis /BCE. El Código de conducta sobre principios para acceso de documentos en su poder preveía que el público tendrá el mayor acceso

a los documentos que posean la Comisión y el Consejo. La Decisión es 93/731. Su vulneración fue el objeto del recurso.

${ }^{6}$ El Real Decreto-Ley 4/2012 considera el silencio administrativo en él contemplado como falta muy grave del funcionario. Cfr. J.L MEILAN GIL "El silencio de la Administración", Anuario da Facultade de Dereito. Universidade da Coruña, 2012.

${ }^{7}$ Cfr. J. L MEILÁN GIL, Categorías jurídicas en el Derecho administrativo,Iustel, Madrid, 2011, pp 22-23 
comprende mejor desde una concepción del Derecho administrativo que no se construya como el Derecho de la Administración, como ha venido sosteniendo una dominante dirección doctrinal ${ }^{8}$ y que se encuentra también en la brillante idea de "un derecho del poder para la libertad. Y esto, se dice, porque hace posible ésta mediante el condicionamiento o limitación de aquél"9. Responden a la construcción propia del Estado liberal - Hauriou es una muestra- con una clara y plausible intención de someter el Poder a control -el recurso por éxces du pouvoir es significativo- y, como habrá ocasión de subrayar, en esas construcciones queda oscurecido el carácter servicial de la Administración, forzada la inclusión de las prestaciones propias del Estado social, difuminado el fundamento de los derechos fundamentales y la libertades públicas reconocidos constitucionalmente, y no consideradas las consecuencias de la definición constitucional del Estado como democrático. Resulta reduccionista ante la asunción del Estado social y democrático de Derecho que no es del caso desarrollar ${ }^{10}$

En 1967, por el contrario, puse el acento en la toma en consideración de los intereses colectivos y hablé de su "regulación y gestión subordinada" 11 , expresión, que, salvo el cambio de intereses colectivos por generales, ha quedado en el artículo 103 de la CE, en cuya redacción intervine, que no figuraba en el anteproyecto: "La Administración sirve con objetividad los intereses generales..." "12. La Administración está sometida al Derecho, no solo a la ley como ha sostenido una tradicional concepción del Derecho administrativo. Es poder, pero vicarial; sirve, pero no determina los intereses generales, ni es titular de ellos. Su fin es ha-

${ }^{8}$ Derecho propio y específico de las Administraciones Públicas en cuanto persona. Un Derecho estatutario hecho de un equilibrio entre privilegios y garantías. E. GARCÍA DE ENTERRÍA, Curso de Derecho administrativo, $6^{\text {a }}$ ed. t.I, Civitas, Madrid, 1993, pp. 38 y ss.

${ }^{9}$ F. GONZÁleZ NAVARRO, Derecho administrativo español, Eunsa, Pamplona, 2a ed. 1993, p. 424.

${ }^{10}$ La originalidad de ese enunciado constitucional "no radica en los términos que contiene tomados cada uno de ellos aisladamente... ni tampoco en una simple agregación o yuxtaposición... sino... en la integración de los tres términos en una totalidad conceptual... vinculados entre sí” Cfr. M. GARCíA PELAYO, "El Estado social y democrático de Derecho en la Constitución española", Obras Completas, Centro de Estudios Políticos y Constitucionales, Madrid, 2009, pp. 1663-64. Sobre la superación del postulado clásico además de la bibliografia citada en nota anterior y posterior cfr. J.L.MEILÁN GIL, Contestación al discurso de J. L. CARRO FERNÁNDEZ- VALMAYOR, Ley y Administración Pública. Un ensayo dogmático sobre la potestad administrativa de la Administración, Real Academia Gallega de Jurisprudencia y Legislación, 2012.

${ }^{11}$ Cfr. J.L. MEILÁN GIL, El proceso de la definición del Derecho administrativo ENAP, Madrid, 1967, pp. 84-85

${ }^{12}$ Cfr. J.L. MEILÁN GIL, Categorías... pp. 182-183.

${ }^{13}$ En ese sentido STS de 27 de marzo de 1986, citada en mi Prólogo al libro de J, RODRÍGUEZARANA La suspensión del acto administrativo en vía de recurso, Montecorvo, Madrid, 1986. El fundamento constitucional se encuentra en el citado artículo 103 que alude al principio de eficacia. 
cerlos efectivos ${ }^{13}$ o garantizar su efectividad en el caso de los derechos fundamentales reconocidos en la Constitución, que son el "núcleo duro", irreductible, de los intereses generales. ${ }^{14}$

Sostenía entonces un concepto material, ratione materiae, para referirme a lo administrativo, más que a un criterio formal o personal de la Administración y a los ejemplos puestos entonces pueden añadirse hoy que puede hablarse de Derecho administrativo aunque el poder de donde emane la actividad sea diferente de la Administración Pública (legislativo, judicial... ). Para acoger esta realidad algún autor ha debido modificar su definición inicial ${ }^{15}$. Es, de otra parte, la que domina en el Derecho comunitario a la hora de definir quién es poder adjudicador en los contratos públicos ${ }^{16}$ y se constata en el Texto refundido de los contratos del sector público que engloba entidades que no son Administraciones públicas, por citar solo un ejemplo.

En hacer efectivos los intereses generales que le vienen predeterminados a la Administración, por iniciativa del Gobierno y el aval del Parlamento radica la "buena administración"17. No es un estándar uniforme y fijo, acentuada esa posible variación por la alternancia en el Poder propia de un Estado democrático y en el caso de los derechos fundamentales vinculada a la voluntad constituyente. Desde esa perspectiva la "buena administración" no responde a bienintencionados principios de Ciencia de la Administración, sino a postulados con fuerza jurídica en un Derecho administrativo acorde con el progreso tecnológico y los requerimientos de la profundización democrática.

Desde la concepción del Derecho administrativo antes adelantada, con referencia al servicio a los intereses generales, en los que se incluyen los derechos fundamentales de la persona, se comprende mejor la "buena administración". Es un servicio a los ciudadanos, no el magnánimo ejercicio de una prerrogativa en re-

${ }^{14}$ De su efectividad habla el artículo 9,2 de la CE. Cfr. J.L. MEILÁN GIL, "Administración Pública, intereses generales e interés público", en Categorías... pp. 184 y ss.

${ }^{15}$ Cfr. F. GARRIDO FALLA, Tratado de Derecho administrativo, vol I. $11^{\text {a }}$ ed. Tecnos, Madrid, 1989, p. 113.

16 STJCE de 20 de septiembre de 1998, asunto 31/87, Gebroeders Beentjes BV/ Estado de los Países Bajos, que tomó para ello como punto de partida que la noción de Estado debe ser objeto de una interpretación funcional.

${ }^{17}$ Por esa tesis se pronuncia J. PONCE SOLÉ, Deber de buena administración y derecho al procedimiento debido, Lex Nova, Valladolid, 2001, pp. 156 y ss con cita en el mismo sentido de BASSOLS COMA. Para TORNOS, op. cit. p. 829 la buena administración "exige algo más que el servir de forma objetiva a los intereses generales". 
lación con los "administrados", expresión que he evitado siempre. En último término, ese carácter servicial, orgullo de una plausible tradición que no debería desaparecer o infravalorarse, la del civil Service o de los servidores públicos, ínsita en la idea del servicio público prestacional, responde en los constitucionalismos actuales de Estados democráticos a la importancia de la dignidad de la persona y los derechos inviolables que le son inherentes... fundamento del orden político y de la paz social, en la expresión del artículo 10 de la CE, una norma jurídica y no un ramillete de proclamas políticas o de exhortaciones éticas.

Desde esa perspectiva se comprende que el acto administrativo como imposición unilateral, resultado del ejercicio de una potestad, ceda posiciones no solo en favor de la prioridad de los derechos fundamentales, sino en el terreno de autorizaciones previas ${ }^{18}$ La pérdida de poder no tiene por qué suponer una apropiación de competencias públicas por la sociedad ${ }^{19}$, sino el reconocimiento del protagonismo de la sociedad ${ }^{20}$ que implica un cambio en la manera de ejercer la Administración pública su función, de acuerdo con un Estado no solo de Derecho y social, sino también democrático y de derechos fundamentales que se imponen a los poderes públicos incluido el legislativo ${ }^{21}$.

El adjetivo "buena" referido a la administración como actividad, más que como estructura y organización, posee consciente o inconscientemente una connotación ética ${ }^{22}$. En esa dirección podría llegar a concluirse que lo ético en la Administración pública coincide con el cumplimiento del fin que justifica su existencia, en la realización del Derecho, teniendo en cuenta que se trata de una actividad humana. Solo las personas son responsables éticamente. Derecho y ética no se confunden. Aun no siendo coincidentes, no son completamente ajenos, sin caer en extremos de teocracia jurídica o de relativismo positivista, que de todo ha habido en la historia o de un modo menos contundente, sin utilizar lo moral para explicar actuaciones que pueden ser explicadas por lo jurídico, como se ha hecho en relación con la desviación de poder.

${ }^{18}$ Cfr. J.L MEILÁN GIL, "Sobre la revisión del carácter instrumental del acto administrativo", $R e$ vista andaluza de Administración Pública, 84, 2012.

${ }^{19}$ En sentido opuesto, J. ESTEVE PARDO, La nueva relación entre Estado y Sociedad: aproximación al trasfondo de la crisis, Marcial Pons, Madrid, 2013.

${ }^{20}$ La protección del medio ambiente ofrece testimonios varios. Por ejemplo, Reglamento 66/2010 del Parlamento y Consejo de la U E sobre el uso voluntario de la etiqueta ecológica.

${ }^{21}$ Sobre la introducción de los derechos fundamentales de la persona en el ordenamiento jurídico español, por una enmienda de mi autoría a la Ley para la reforma política de 1977, cfr. J. L. MEILÁN GIL, Categorías jurídicas... pp. 184-186.

${ }^{22}$ Amplia y brillantemente en J. RODRÍGUEZ-ARANA, La dimensión ética de la función pública, INAP, Madrid, 2013. ROMEU FELIPE BACELLAR FILHO, Relexoes sobre Direito administrativo. Forum, Belo Horizonte, 2009. 
Aunque la realización del Derecho que concierne a la Administración no agote el alcance de la dimensión ética de la actuación de sus autores, en gran medida el comportamiento conforme a Derecho es síntoma de comportamiento ético. Forma parte de la profesionalidad exigida a los servidores públicos y de ahí la importancia de una continua formación. Pero "la buena administración", no queda reducida al buen comportamiento de las personas; es también aplicable a la Administración como organización a la que es muy forzado atribuir una calificación ética, aunque puede hablarse de estructuras "inmorales".

El Derecho, en su conjunto, tiene sus limitaciones. Puede y debe orientar y dirigir y estimular el buen hacer y también castigar y disuadir, por tanto, de comportamientos indebidos así como disponer de modo que sean difíciles de llevarse a cabo, haciendo trasparente la actuación pública. Las claves para una actuación ética en la Administración Pública habrá que encontrarlas no pocas veces fuera de ese ámbito. Y en todo caso, es indispensable la colaboración de una conciencia social que estimule la "buena administración".

Con frecuencia la buena administración es acompañada por el buen gobierno y en ocasiones se identifican. En ese sentido se habla de Administración Bush o Administración Obama. A estas alturas de la historia pueden deslindarse ambos conceptos. Las políticas públicas son definidas por el Gobierno o a su iniciativa, incluso ocupando el espacio de la ley cuando tiene mayoría absoluta en el Parlamento y opera mediante Decretos-Leyes. A la Administración incumbe ejecutarlas, aunque también el propio Gobierno puede administrar.

La "buena administración" implica que la Administración realice su cometido de modo adecuado a la política diseñada. El gobierno puede acordar una política de obras públicas. La ejecución se concretará en la suscripción de contratos entre la Administración y los particulares. Una defectuosa preparación de los pliegos de cláusulas administrativas revelaría una mala administración. La contratación pública se convierte en un medio para la realización de políticas públi$\mathrm{cas}^{23}$, como es ya paradigmático en la UE para hacer efectivo la sostenibilidad del medio ambiente como reconocimiento de la solidaridad intergeneracional, que ha propiciado la expresión de Green public procurement ${ }^{24} \mathrm{u}$ otros objetivos políticos o sociales ${ }^{25}$.

${ }^{23}$ Cfr. J. L. MEILÁN GIL, "Las prerrogativas...

${ }^{24}$ Cfr. J. PERNAS GARCíA, Contratación pública verde, la Ley, Madrid, 2011. Se trata, en definitiva, de "todos - con una proyección de futuro- tienen el derecho a disfrutar de un medio ambiente adecuado para el desarrollo de la persona, así como el deber de conservarlo" (artículo 45 de la CE).

${ }^{25}$ Cfr. J. PERNAS GARCíA (Coord.) Contratación pública estratégica, Thomson Reuter Aranzadi, 2013. 
El deslinde de gobierno y administración no siempre es fácil. El artículo 97 de la CE expresa, no obstante, con claridad que "el Gobierno dirige la política interior y exterior, la Administración civil y militar". La Administración no formula las políticas públicas y se desnaturaliza su función si se politiza contaminándose de la alternancia en el Gobierno, porque sería proclive a no actuar con la imparcialidad constitucionalmente requerida (artículo 103,3 de la CE).

Aunque sea relativamente reciente la utilización de la "buena administración" cuenta detrás con una larga historia.

\section{LA IDEA DE BUEN GOBIERNO}

\section{La justificación del poder público.}

La justificación del poder público se ha formulado de varias maneras y con diferentes nombres a lo largo de la historia, a la que va asociada una amplia lista de ilustres pensadores de cita innecesaria. Tiene que ver con los fines que se propone la organización política. Dicho de una manera rápida, con técnica impresionista, el ejercicio del poder público se justifica por y para la procura del bien común, el vivere bene de los miembros de la sociedad política en expresiones clásicas de Aristóteles"(eudamonia) y Tomás de Aquino (virtus) ${ }^{26}$, la felicidad de los súbditos y el bienestar en la época de la Ilustración ${ }^{27}$ y el Despotismo ilustrado -"Mi dolor, dirá el emperador José II- es no poder hacer a todo el mundo feliz-, en la Declaración de independencia de los EEUU - the pursuit of happiness, como un derecho- o como proclamó la Constitución de Cádiz en su artículo 13: "El objeto del Gobierno es la felicidad de la Nación, puesto que el fin de toda sociedad política no es otro que el bien estar de los individuos que la componen”.

Algunas de las expresiones recordadas revelan que lo que hoy se entiende por gobierno, administración y ética aparecen mezcladas en la fundamentación y ejercicio del Poder público. La evolución histórica puede ser examinada como un proceso de diferenciación de esos ámbitos del quehacer humano.

En ese sentido J.M.GIMENO FELIU, "La ley de contratos del sector público ¿una herramienta eficaz para garantizar la integridad? Mecanismos de control de la contratación administrativa en la contratación administrativa", REDA, 147, 2010 en donde se habla de la contratación como herramienta al servicio de los poderes públicos para el cumplimiento de sus fines o sus políticas públicas.

${ }^{26}$ Cfr. S. Thomae Aquinitatis, In decem libros Aristotelis ad Nicomachum expositio, Marietti, 1964, I lectio I,4 y In octo libros Politicorum Aristotelis expositio, Marietti, 1996, I lectio, 11 y 31.

27 Cfr. J.L. MEILÁN GIL, J.L. Categorías juridicas en el Derecho administrativo, Iustel, Madrid, 2011, pp. $177-180$ 
En ese sentido, principios para el buen manejo de la res pública se encuentran, por ejemplo, en Aristóteles (La Política), en Cicerón (De legibus), en Santo Tomás (De Regimine Principis). Esa corriente se desplaza a lo que podría denominarse filosofía política: son los consejos al Príncipe para el buen gobierno, criterios de experiencia o de moral en el gobierno del país y, simultáneamente, límites del poder. Así el Defensor civitatis de Marsilio de Padua o las obras de Maquiavelo (Discursos sobre las décadas de Tito Livio) y el celebérrimo El Príncipe, anotado por Napoleón Bonaparte ${ }^{28}$, o el menos conocido Norte de Príncipes de Antonio Pérez ${ }^{29}$.

El absolutismo del Antiguo Régimen se sintetizaba por los revolucionarios franceses y tratadistas del Derecho público coetáneos y posteriores en el axioma Rex, legibus solutus, aunque en expresión de Vázquez de Menchaca estaba legibus alligatus. No es cuestión de ahondar en el análisis. Bastará reconocer en esa ligazón la vertiente moral inherente durante centurias a la concepción de la Monarquía.

En el ciclo de evolución del Estado, por lo que ahora interesa, una etapa se corresponde con la gute Policey, la bonne police como expresión de buen gobierno. En ella "se mezclan el aristotelismo tradicional y el espíritu de organización del Estado moderno" 30 . De ahí tomarán su nombre los heterogéneos escritos que tienen por objeto la gestión de los asuntos del Estado. También será denominada cameralística, por el carácter práctico, deducido de la actividad desarrollada en las distintas dependencias (camera, kammer).

La estrecha vinculación a la práctica y la falta de un método adecuado en el tratamiento y selección de las materias daban como resultado un fuerte carácter asistemático que se reflejaba en la mezcla de juicios de valor, descripciones, propuestas de reformas, con un carácter paternalista y hedonista en su orientación básica.

Existían reglamentos de administración y textos jurídicos, pero también la ética estaba presente en catálogos de las "virtudes del buen funcionario". Para el buen gobierno el Príncipe precisaba de servidores que, además de ser experimentados y hábiles, debían ser leales y piadosos, de acuerdo con el pensamiento de la época.

\footnotetext{
${ }^{28}$ Espasa-Calpe, Madrid, $13^{\mathrm{a}}$ ed, 1973

${ }^{29}$ Norte de Príncipes, Virreyes, Presidentes, y Governadores, y Advertencias políticas sobre lo público y particular de una Monarquí, Espasa-Calpe, Madrid, 1969.

${ }^{30}$ Cfr. MICAEL STOLLEIS, Histoire du Droit Publique en Alemagne. Droit publique impériale et science de la police. 1600-1800, pp. 509 y 546.
} 
Se imponía una labor de sistematización, a la que están vinculados los nombres de Delamare (Traité de la Police) y de von Justi (Grundsatze des Polizeitwisenschaft $^{31}$. El estudio científico se mezcla con consideraciones acerca de la conveniencia o no de la intervención del Estado en una determinada materia. Es sintomático el contenido de la obra dedicada a la agricultura, al comercio y manufacturas y las costumbres que deben seguir los súbditos y todo para procurar la felicidad pública; pero se establece ya entonces la relación entre los fines del Estado y los medios para conseguirlos y siempre teniendo en cuenta la realidad práctica circundante.

La transición de la ciencia cameral a la Ciencia de la Administración del siglo XIX está marcada por la obra de von Mohl (1799-1875), que establece la diferencia entre Derecho, Constitución y Administración. Un paso decisivo lo da Lorenz von Stein (1815-1890) con su monumental Verwaltungslehere que intenta reducir el caos cameralista a sistema ${ }^{32}$. Es posible porque existe una idea de la Administración, que da unidad a la actividad del Estado. La Administración es la medida de la fuerza y de la acción del Estado. Es la Constitución en su realización dinámica; la Administración como "Constitución en acción".33

Merece la pena detenerse brevemente en el planteamiento de von Stein por la significación de su intento y la deriva que va a tener el estudio de la Administración. En él la consideración jurídica de la Administración, lo que hoy se llama Derecho administrativo, no es algo independiente de la Ciencia de la Administración: ésta es una ciencia unitaria que tiene por objeto la Administración globalmente considerada, no exclusivamente desde un punto de vista formal. Siguiendo la línea cameralista se fija en la actividad real del Estado, que se encuentra condicionada por una serie de datos económicos, históricos y sociológicos sin los cuales no se explica.

La profecía sobre el papel integrador de la Ciencia de la Administración resultó fallida en el tiempo. Lo que se impondrá será una consideración dominante de la aproximación jurídica a la Administración, la preocupación por el sometimiento de la Administración al Derecho, característico del Estado de Derecho, el Rechstaat, que liderará la figura de Otto Mayer. En los casos en los que se

31 Traducción al español desde el francés de PUIG Y GELABERT Elementos generales de la Policía (1784). Sobre la cuestión cfr. A.GALLEGO ANABITARTE, Formación y enseñanza del Derecho Público en España (1769-2000), pp. 76-85.

32 Una corriente mayoritaria considera a la Ciencia de la Policía como antecedente de la Ciencia de la Administración. En ese sentido, M. BAENA del ALCÁZAR, Los estudios sobre la Administración en la España del siglo XVIII, Instituto de Estudios Políticos, Madrid,1968

33 Cfr. Harmut MAURER, Derecho administrativo, trad. española, Marcial Pons, Madrid, 2011. 
conserva el nombre de Ciencia de la Administración, como ha sucedido en España o Italia, se la ha concebido como "el pariente pobre del Derecho administrativo", una especie de cajón de sastre en el que se recogerían los desechos del estudio de la Administración, lo que no es susceptible de estudio jurídico, incluso cuando éste se ocupa de la organización.

Será preciso llegar al siglo XX para que se lance la idea de la "vuelta a von Stein (Smend, Forsthoff), de alguna manera similar a la "vuelta a Colmeiro" patrocinada en España por Jordana de Pozas en los años 40 del pasado siglo. Ese movimiento defiende, en definitiva, la consideración, junto al Derecho, de lo existente por debajo de las formas jurídicas, es decir, la realidad económica, sociológica que las normas jurídicas pretenden vaciar, la perspectiva histórica que evidencie su origen y evolución para lograr, en consecuencia, un criterio para determinar si es oportuno o inoportuno su mantenimiento.

El itinerario en los EEUU no es coincidente. Los cambios sociales que se operan a finales del siglo XIX y comienzos del XX influyen en la actividad y estructura del Estado. El aparato estatal aumenta, se complica, no puede manejarse de un modo propio de aficionados y de personas que cambian al compás de los vaivenes políticos, de acuerdo con el spoil's system. Además de ineficiencia, el turnismo político facilita la corrupción. Los primeros estudios no proceden de juristas, sino de especialistas en ciencias políticas. Un referente paradigmático es el artículo publicado en 1887 por Woodrow Wilson, más tarde Presidente, con el título "The Study of Administration". Su lema es "Public Administration out Politics".

Los estudios sobre la Administración pública están presididos por una idea de reforma. Se trata de hacer más efectiva la responsabilidad del Ejecutivo por su actividad de gobierno, de hacer más neutrales y más competentes a los funcionarios, de conseguir que la actuación administrativa se acerque al nivel de eficiencia de la empresa privada, de acuerdo con el protagonismo característico de la sociedad en ese país.

En todo caso, conviene retener que en los EEUU los estudios sobre la Administración Pública no corresponden al Derecho administrativo, sino a los cultivadores de la ciencia política. Aquel tiene una declarada orientación garantista: cuáles son los poderes de las agencias administrativas y sus límites; con qué medios se cuenta para mantenerlas dentro de sus límites. ${ }^{34}$

${ }^{34}$ Cfr. SCHWARTZ, B. Administrative Law, Little, Brown and Company, Boston-Toronto, p. 3. 


\section{Identificación entre gobierno y administración}

La diferenciación entre gobierno y administración queda difuminada durante el constitucionalismo basado en la separación de poderes, abanderada por los revolucionarios en Francia. La Administración queda embebida en el Poder ejecutivo y en la Europa post napoleónica, en virtud del principio monárquico, que supuso una transacción entre los principios revolucionarios y las Monarquías: el Rey como cabeza del Ejecutivo participará en el poder legislativo.

No hay en el plano científico una separación entre gobierno y administración, de lo que son muestra los pioneros del Derecho administrativo en España ${ }^{35}$. En Gómez de la Serna (1843) no se realiza esa distinción. La ejecución de las leyes se lleva a cabo por dos medios: "uno es el de la acción y otro el de la decisión; esto hace que el Poder Ejecutivo se ha dividido en Poder Administrativo o Ejecutivo y en Poder Judicial". Para Colmeiro (1876): "Administrar significa gobernar, en cuanto gobernación equivale al ejercicio del Poder ejecutivo".

Esos pioneros hablan de la ciencia administrativa al referirse a la Administración. En Javier de Burgos, la Administración, que acompaña al hombre antes de nacer y durante toda su vida hasta después de la muerte, es "más ciencia que Derecho" es "la más vasta y la más útil de las ciencias morales"36. Para Ortiz de Zúñiga, la economía política preparó el camino para el descubrimiento de la ciencia más importante aún conocida con el nombre de Administración. La ciencia de la administración sería la necesidad de las naciones modernas ${ }^{37}$. Posada Herrera hablará de que todo lo que tienda a destruir el principio de la sociedad y detener su progreso "será contrario a las reglas de la buena administración"38 Los planes de estudio de las Universidades en el siglo XIX, reflejan la vinculación de la Administración a otras disciplinas académicas ${ }^{39}$

${ }^{35}$ Cfr. MEILÁN GIL, J L, Lectura de clásicos del Derecho administrativo. Andavira, Santiago de Compostela, 2012, pp. 144 y 205, respectivamente.

${ }^{36}$ Cfr. J.L MEILÁN GIL, Lecturas.. 101-106. "Hacer bien es la incumbencia esencial, la suma de todas las atribuciones de la Administración", dice su Instrucción de 1833 a los Subdelegados de Fomento, cit. por A. SÁNCHEZ BLANCO, "El derecho a una buena administración. Control de desviaciones" en Derechos y garantías de l ciudadano. Estudios en homenaje al profesor Alfonso López Moreno, Coord. F. LÓPEZ MENUDO, Iustel, Madrid, 2011.

${ }^{37}$ Para GALLEGO ANABITARTE, refuerza su tesis de que empalma con el tradicional mando político, el económico y gubernativo Formación... p.166.

${ }^{38}$ Lecciones de Administración, ed. de 1978, p. 52, sin un significado específico de la expresión.

${ }^{39}$ Cfr. J L MEILÁN GIL, Los planes universitarios de enseñanza en la España contemporánea, ENAP, Madrid, 1970. En el plan de 1850, por ejemplo, la sección de Administración era una de las cuatro que constituían la Facultad de Filosofia. En la ley Moyano forma ya parte de la Facultad de Derecho. 


\section{Diferenciación entre buen gobierno y buena administración ${ }^{40}$}

Más que una separación orgánica entre Gobierno y Administración, tanto en la doctrina científica como en la legalidad constitucional, se ha ido abriendo paso una distinción funcional entre gobierno y administración.

En ese sentido, Posada Herrera (1842): "Las funciones del Gobierno son de una esfera más elevada que las de la Administración, son las que están atribuidas constitucionalmente al Poder real; la Administración tiene funciones que aunque menos importantes, no son menos provechosas al bienestar y felicidad del país". ${ }^{11}$

Según Otto Mayer, “para toda actividad que no sea ni justicia, ni legislación se introduce la palabra administración, no para remplazar al vocablo Gobierno (Regierung), sino para designar una nueva rama de la actividad, la cual desprendiéndose también del gobierno se ubica al lado de la justicia" ${ }^{2}$. El gobierno consistiría en "la alta dirección, el impulso que parte del centro para hacer marchar los asuntos en el sentido de una buena política y el interés general".

En una línea equivalente se pronuncia Hauriou. La función administrativa consiste esencialmente "à faire les affaires courants du public" y la función de gobierno "à resoudre les affairs exceptionelles", que interesan a la unidad política y a velar por los "grands intéréts nationaux" 43 . La diferenciación no está explícitamente formulada, por ejemplo, en los EEUU. La CE, en cambio, como se recordó anteriormente, ofrece base para la distinción.

$\mathrm{El}$ anterior recorrido permite distinguir en la actualidad entre buen gobierno y buena administración. El buen gobierno es el que mejor responde a las aspiraciones de la sociedad. La prueba decisiva en un sistema democrático viene manifestada por el apoyo o respaldo que tenga en los electores. El juicio jurídico es inapropiado.

Se trata de opciones de carácter político, vinculadas a posiciones o concepciones ideológicas que responden al pluralismo inherente al sistema democrático.

${ }^{40}$ No se hará referencia al término gobernanza reiteradamente utilizado en la actualidad. Sobre ello cfr. J.L. MEILÁN GIL, Aproximación al Derecho administrativo Global, Editorial Derecho Global, Sevilla, 2011.

${ }^{41}$ JL MEILÁN GIL, Lecturas... p. 161.

${ }^{42}$ Cfr. Le droit administratif allemand, París, 1903. Para su comprensión es preciso tener en cuenta su concepción del acto administrativo como ejecución o aplicación de la ley de un modo paralelo a la sentencia. Cfr. MEILÁN GIL, J L, Categorias jurídicas en el Derecho administrativo, Iustel, Madrid, 2011

43 Cfr. M HAURIOU, Précis élementaire de Droit administratif, $5^{\mathrm{a}}$ ed., puesta al día por André HAURIOU, p. 11. 
Se concretan en políticas públicas, que pueden ser objeto de análisis por los cultivadores de la ciencia política, por politólogos; no desde la ciencia jurídica, hecha la salvedad de comprobar el respeto a la Constitución. Desde aquel punto de vista pueden ser examinadas y propuestas las reformas en materia económica, de salud, de educación, de medio ambiente y tantos otros capítulos de la acción del Estado.

La buena administración tiene un ámbito acotado por esas políticas públicas, con el sometimiento pleno a la ley y al Derecho. En ese sentido podría sostenerse que toda reforma administrativa que tiende a hacer realidad el paradigma de la buena administración, ha de insertarse en el ordenamiento jurídico, desde el que puede razonarse la idoneidad de la organización, de las formas de actuación y la regulación del régimen de los agentes para la realización de las políticas públicas, sin que exista una mezcla inapropiada de aproximaciones científicas diferentes.

Adoptado, por ejemplo, el protagonismo del mercado en actividades que previamente eran de titularidad pública aunque fueran gestionadas por particulares, y aceptada la creación de agencias reguladoras, un juicio sobre la buena administración no consiste tanto en valorar la orientación que presidió aquella decisión política cuanto en analizar si la organización administrativa levantada responde adecuadamente a la finalidad perseguida por la decisión política.

En ese sentido la función de las referidas Agencias tiene que ver con la singularidad de los sectores liberalizados, en algunos casos de gran complejidad técnica, como sucede en el de las telecomunicaciones o el energético. Esa circunstancia requiere una especialización en aras de que puedan cumplirse de un modo satisfactorio los fines señalados a las Agencias, que no se pueden lograr con una unificación de entidades, acordada desde una indiscriminada reducción del gasto público. La mala administración resultante proviene de una decisión equivocada, de un mal gobierno.

Apurando el ejemplo, existe consenso en que las agencias reguladoras tengan la necesaria independencia. Esa nota se extiende a lo que con diferentes finalidades puede llamarse Administración instrumental, entes instrumentales, cuyo análisis excede el propósito actual. ${ }^{44}$ No resulta excesivo sostener que la razón de esa independencia radica en la necesidad de un distanciamiento del Gobierno en materias que, por una u otra razón, se considera que rebasan el ejercicio ordina-

${ }^{44}$ Cfr. MEILÁN GIL, J L, La Administración Pública en perspectiva, Universidade da Coruña, 1996, pp. 511 y ss. 
rio del poder gubernamental. Se trata de conseguir una "neutralización" del Gobierno, cualquiera que sea su coloración política, en determinados sectores: protección de datos personales, energía nuclear, radio y televisión públicas, Banco central, entre otros.

A veces, esa independencia no es una elección libremente adoptada por un Estado miembro de la Unión Europea, sino obligada o sugerida por ésta. Es el caso reciente, en el marco de las medidas requeridas para cumplir con el objetivo marcado de reducción del déficit público, la creación de una Unidad independiente con la finalidad de que siga o vigile el cumplimiento de los objetivos comprometidos por las Administraciones Públicas en cuanto a endeudamiento.

Una sentencia del Tribunal de Justicia de la Comunidad Europea de 16 de octubre de 2012 declaró que no era conforme con el derecho comunitario la Comisión austriaca de protección de datos personales por no cumplir con la obligación de actuar con la completa independencia que se exige a la autoridad para el control en materia de datos personales, porque su administrador es un funcionario federal sometido a supervisión jerárquica y la secretaría está integrada en la Cancillería federal.

\section{LA BUENA ADMINISTRAGIÓN}

\section{Administración Pública y administración privada: excurso.}

La Administración Pública, se ha adelantado, tiene como finalidad, como misión podría decirse, servir con eficacia los intereses generales. Desde esta función han de considerarse reformas que tiendan a mejorarla al servicio, en definitiva, de los ciudadanos. Es lo que distingue de las empresas privadas. Es prudente, por ello, alertar de afirmaciones que pueden resultar equívocas por su ambivalencia, en el sentido de que toda agregación social precisa una cierta administración.

El adjetivo público es determinante para entender de qué se habla. El modelo de la Administración pública no ha de buscarse en el sector privado, aunque algunas de sus técnicas puedan ser aprovechadas. Como se ha dicho con autoridad (Wolff) ${ }^{45}$, la Administración pública, como la Administración privada es cuidado de asuntos, de negocios (Geschaft), pero la expresión es equívoca, porque la esencia de aquella no viene determinada por la consecución de ganancias. Aun cuando no se excluyan, su actividad es función (Amt) y no negocio (Geschaft). Es el fin lo que diferencia unas y otras administraciones.

${ }^{45}$ Verwaltungsrecht, $5^{\mathrm{a}}$ ed. Munich y Berlin, 1963, p. 12. 
La eficiencia no se mide por los mismos parámetros en la Administración pública y en la empresa privada. Eso no es óbice para que estudios y prácticas experimentadas en el sector privado puedan ser adaptados a la Administración Pública; pero el criterio de evaluación es obviamente diferente en uno y otro caso. El rendimiento de la eficiencia, la productividad, la organización racional del trabajo se mide en función de las peculiares misiones de una y otra, sin necesidad de identificarlas. En el fondo, puede existir un cierto posicionamiento ideológico, en el que no es necesario insistir, o un planteamiento táctico para hacer más viable la introducción de reformas. No es infrecuente que frente a una impresión negativa del funcionamiento de la Administración pública, explicable por la conciencia que los ciudadanos tienen de sus derechos, se presente la eficiencia de la empresa privada.

\section{2. la "buena administración", como principio jurídico.}

La buena administración ha sido -y es- utilizada por la doctrina científica, por los tribunales y por la legislación como principio jurídico. En ese sentido las normas de buena administración "deben dirigir toda la de la Administración Pública", en palabras de García Trevijano, que "no son iguales a la moderna ciencia de la administración. ${ }^{46}$ Como "principio rector que impone un mandato de optimización" la califica Tornos Mas, "un nuevo instrumento dentro del proceso de continua perfección de los mecanismos de protección del ciudadano frente al poder público". ${ }^{47}$

En ocasiones se emplea para calificar como contrario a ella el comportamiento de la Administración, declarado judicialmente por no ser conforme a Derecho. Así se comprueba en un celebrado trabajo del profesor García de Enterría sobre "la interdicción de la arbitrariedad en la potestad reglamentaria" del año 1959, a propósito de una sentencia del Tribunal Supremo, principio que fue incorporado al artículo 9,3 de la Constitución ${ }^{48}$. Se hablaba del "deber de buena administración" (arbitrium boni administrationis). En análoga dirección me pronuncié a propósito de una sentencia del Tribunal Supremo que anuló la aprobación de un plan urbanístico utilizando el procedimiento de urgencia que restringe los elementos de defensa de los afectados: en "la exigencia del procedimiento ordinario -el procedimiento debido- frente al que habilita la urgencia hay algo más

\footnotetext{
${ }^{46}$ Citado por J.PONCE SOLÉ Deber... p. 152.

${ }^{47}$ Cfr. "El principio... pp. 830 y 841.

${ }^{48}$ Fue publicado en el $n^{\circ} 30$ de la RAP, superando la inercia de la no revisión judicial de los reglamentos.
} 
que una picajosidad. No solo se trata de que no disminuyan las garantías del ciudadano, sino también que se asegure la buena administración". 49

En la doctrina científica se ha intentado también deducir el principio o deber de buena administración del artículo 103 de la Constitución que al hablar de objetividad y eficacia supondría su consagración implícita como marco de la actuación de la Administración..$^{50}$

Existen textos legislativos que se refieren explícitamente a la buena administración. Suelen citarse la Exposición de Motivos de la LJCA de 1956 en la que intervinieron ilustres profesores, Ballbé y González Pérez fundamentalmente: "las infracciones administrativas se muestran realmente no tan sólo como una lesión de las situaciones de los administrados, sino como entorpecimiento a la buena y recta administración".

El artículo 25,1 del Texto refundido de la Ley de contratos del sector público (Real Decreto legislativo 3/2011) dice que "podrán incluirse cualesquiera pactos, cláusulas y condiciones, siempre que no sean contrarios al interés público, al ordenamiento jurídico y a los principios de buena administración”.

La Exposición de Motivos de la Ley 7/2007 de 12 de abril sobre el Estatuto básico del empleado público proclama que "las Administraciones y entidades públicas de todo tipo deben contar con los factores organizativos que permitan satisfacer el derecho de los ciudadanos a una buena administración, que se va consolidando en el espacio europeo".

En la jurisprudencia aparece esporádicamente la referencia a la buena administración como criterios o principios, a veces con alusión a la moderna doctrina científica, ${ }^{51}$ junto con otros, como el de proporcionalidad.

\section{La "buena administración" como derecho fundamental.}

La expresión "buena administración" ha dejado de ser una aspiración meramente programática e incluso un principio jurídico ${ }^{52}$ para convertirse en un de-

${ }^{49}$ J.L. MEILÁN GIL, "La dimensión temporal de la Ordenación urbanística”, Revista de Derecho urbanístico y Medio ambiente, num. 145. 1995, p. 933.

${ }^{50}$ En ese sentido, M. BASSOLS COMA, cit. por J. PONCE SOLÉ Deber... p.154 que se adhiere a esa tesis.

${ }^{51}$ Cfr. J. PONCE SOLÉ, Deber... pp. 150-152.

52 Para TORNOS, op. cit.p. 833 "la buena administración debe concebirse no tanto como un nuevo derecho de los ciudadanos, sino como un principio rector de la actuación de las administraciones públicas" 
recho fundamental, en el caso del artículo 41 de la Carta de derechos fundamentales de la Unión Europea, proclamada por el Consejo Europeo de Niza de $8 / 10$ de diciembre de $2000 .^{53}$

En síntesis consiste en que toda persona tiene derecho a que las instituciones, organismos y órganos de la UE "traten sus asuntos imparcial y equitativamente y dentro de un plazo razonable". Esta expresión permite un entendimiento no necesariamente ligado al sentido garantista que domina, sin embargo, en la concreción que de ese enunciado general se realiza en los apartados siguientes del artículo: derecho de toda persona a ser oída antes de que se adopte una medida individual que le afecte desfavorablemente, a acceder al expediente que le concierna, obligación de la Administración a motivar sus decisiones, posible reparación de daños.

Se ha planteado la cuestión de elucidar en qué medida ese derecho fundamental obliga a los Estados miembros a la vista del artículo 51 de la misma Carta, según el cual sus disposiciones "están dirigidas a las instituciones, órganos y organismos de la Unión, respetando el principio de subsidiariedad, así como a los Estados miembros únicamente cando apliquen el Derecho de la Unión. Por consiguiente, éstos respetarán los derechos, observarán los principios y promoverán su aplicación, con arreglo a sus respectivas competencias".

Una primera interpretación consistiría en entender que el derecho fundamental de la Carta se refiere a actuaciones de los entes de la Unión Europea. En ese sentido podría esgrimirse una STJ (Sala Quinta) de 7 de noviembre de 2013 que entiende que no procede la petición de decisión prejudicial planteada por un tribunal italiano por haber sido formulada con un improcedente carácter consultivo y "cuando el Derecho nacional prevé ya la aplicación" en ese caso de la obligación de motivar el acto. El defecto formal de la petición parece cubrir la decisión del Tribunal. La remisión al Derecho del Estado miembro no es obstáculo, en mi opinión, sino todo lo contrario a que el supuesto ya previsto en el Derecho positivo del Estado miembro sea elevado a la categoría de derecho fundamental.

Después de la nueva redacción del artículo 6 del Tratado de la Unión acordado en Lisboa el 13 de diciembre de 2007 por la que la Carta de los Derechos

\footnotetext{
${ }^{53}$ Sobre los precedentes de diferentes ordenamientos nacionales cfr. B. TOMÁS MALLÉN, El derecho fundamental... pp. 104 y ss. Las Constituciones de Portugal y Finlandia se refieren expresamente a la buena administración. En otros países, como sucede en el ordenamiento español, se reconoce elementos que integran el contenido del nuevo derecho fundamental: motivación, audiencia, plazo razonable para decidir...En ese sentido la Convención europea de derechos humanos puede considerarse como un precedente.
} 
Fundamentales de la Unión Europea "tendrá el mismo valor jurídico de los Tratados", puede entenderse despejada la duda expresada anteriormente. El derecho a la buena administración se incorpora, como Estado miembro de la UE, al ordenamiento jurídico español que específicamente incorpora los derechos fundamentales a la Constitución y que se refuerza en su artículo 10.2 que dispone que las normas relativas a los derechos fundamentales "se interpretarán de conformidad con... los tratados y acuerdos internacionales sobre las mismas materias ratificados por España".

El avance es de una extraordinaria importancia. No es necesario insistir en la naturaleza y significación jurídica de esa institución. No solo son derechos subjetivos, sino que vinculan, en tanto Derecho objetivo, a todos los poderes del Estado como se reconoce en el artículo primero de la Ley fundamental de Bonn y en el 53 de la Constitución española

El contenido descrito constituiría el núcleo fundamental del derecho del mismo nombre a la buena administración, que se sitúa en un nivel constitucional. Viene a otorgar ese rango a algunos de los supuestos contenidos en el derecho a la buena administración que eran ya reconocidos por el ordenamiento jurídico español. En ese sentido, por ejemplo, la motivación se enlaza con la caracterización del Estado como democrático de Derecho. Alcanzaría también a reglamentos y disposiciones generales, tradicionalmente consideradas como campo propio de la discrecionalidad e incluso exentas de control jurisdiccional en algunas etapas del ordenamiento jurídico.

No existe un modelo único de buena administración, pero al menos el derecho fundamental indica que existe algo que es sustancial, que puede ser común a todas las Administraciones. La regulación de ese derecho fundamental es deudora de una arraigada concepción del Derecho administrativo, construido sobre la óptica del control de la Administración Pública, en garantía de los derechos de los ciudadanos, cuya relevancia es innecesario subrayar. Pero, incluso desde esa perspectiva, la consideración como fundamental del derecho a la buena administración permite avanzar en el aseguramiento de su realización.

La consideración de la Administración pública como servidora de los intereses generales conduce a dejar de considerarla como el "personaje poderoso que desciende del Olimpo" en frase de Hauriou ${ }^{54}$, enjoyada de privilegios, como todavía se lee en leyes y libros científicos. La motivación como contenido del derecho fundamental a la "buena administración" deja de ser un mero elemento del

\footnotetext{
${ }^{54}$ Cfr. Précis... p.3
} 
acto. Resolver en un plazo razonable adquiere mayor fuerza jurídica desde su reconocimiento como derecho fundamental y obliga a un comportamiento diligente de la Administración. Con expresivas palabras se ha dicho en sede judicial que el silencio de la Administración "no es una autorización para no resolver cuando le venga en gana" ${ }^{55}$ En materia de silencio no basta que el remedio del incumplimiento sea la obligación de dictar un acto expreso aunque sea confirmatorio del otorgamiento del derecho; existe una responsabilidad que merece la correspondiente sanción.

La consideración de la "buena administración" como derecho fundamental tiene consecuencias jurídico-procesales propias. El artículo 53,2 de la CE dispone que cualquier ciudadano podrá recabar la tutela ante los Tribunales ordinarios por un procedimiento basado en los principios de preferencia y sumariedad y, en su caso, a través del recurso de amparo ante el Tribunal constitucional. Aquel procedimiento se regula en el título V de la LJCA, cuyo análisis no es del caso realizar ahora. La motivación del acto deja de ser un mero elemento de éste para constituirse en un derecho fundamental conectado con el también fundamental a la tutela judicial efectiva. Lo mismo sucede en el caso de la no resolución, "indebida dilación", especialmente importante en materia de silencio positivo, de modo que no corran los plazos para la interposición del recurso en tanto no se dicte la obligada resolución expresa, al menos cuando se trate de una relación bilateral entre el ciudadano y la Administración. Por qué el ciudadano que entiende que el silencio de la Administración es positivo tendría que interponer el recurso en el mismo plazo que en el caso del silencio negativo. Este se ha configurado tradicionalmente en favor del interesado, el no titular del derecho reconocido. Lo contrario que sucede en el caso del silencio positivo. En ese sentido habría que considerar la posibilidad de un recurso autónomo y directo contra ese amplio "silencio" de la Administración, si perdurase más allá del plazo de seis meses previsto en el artículo 46 de la LJCA o, incluso sustituir ese plazo legal que merma la defensa de los afectados por el silencio al privar de la motivación de la Administración, que también forma parte del contenido del derecho fundamental a la buena administración. En todo caso una razón más para reflexionar sobre la tradicional regulación del "silencio administrativo" 56

Como derecho fundamental puede ser recurrido también ante el Tribunal Europeo de derechos humanos, en relación con el artículo 6 del Convenio Euro-

\footnotetext{
55 STS. de 17 de abril de 1990, ponente el profesor F. GONZÁLEZ NAVARRO.

${ }^{56}$ Cfr. J.L. MEILÁN GIL, "Sobre la revisión del carácter instrumental del acto administrativo", $R e^{-}$ vista Andaluza de Administración Pública, 84, 2012.
} 
peo del mismo nombre que se refiere al "derecho a un proceso equitativo", que concuerda con el citado 41 de la Carta Europea en cuanto al fondo, aunque éste se refiere a entes administrativos y no a tribunales. El Tribunal de Luxemburgo se ha pronunciado sobre esta cuestión en numerosas sentencias ${ }^{57}$. Aunque el citado artículo habla de litigios sobre derechos y obligaciones de carácter civil o sobre el fundamento de acusaciones en materia penal también ha actuado sobre decisiones de órganos jurisdiccionales administrativos, sobre actos de autoridades administrativas, por falta de independencia del órgano juzgador ${ }^{58} \mathrm{o}$, con mayor frecuencia, por superación del "plazo razonable" para decidir ${ }^{59}$ o porque una decisión insuficientemente motivada puede llevar a una violación de la libertad de expresión ${ }^{60}$

También el Tribunal de Justicia de las Comunidades, como es comprensible, ha resuelto asuntos en los que se hace referencia a la "buena administración", en estos precisos términos, o a alguno de los supuestos en que se concreta según el citado artículo 41 de la Carta de derechos fundamentales de la UE ${ }^{61}$. En ese sentido, por ejemplo, en una STJCE de 12 de junio de 2005 asunto Comisión/CEUA Santé Animal sobre uso de la progesterona, aunque no se estima el recurso, se afirma que la inactividad de la Comisión entre el 1 de enero de 2000 y 25 de julio de 2001 no constituye una violación manifiesta y grave del "principio de buena administración", como se pretendía, que genera responsabilidad de la Comunidad.

\footnotetext{
${ }^{57}$ De fácil comprobación, de las cuales se contiene referencias en V. BERGER, Furisprudence de la Cour Europeen des droîts de l'homme, $8^{\text {a }}$ ed., Sirey, París, 2002, pp. 149-332. También en B. TOMÁS MALLÉN, El derecho... pp. 265-270.

${ }^{58} \mathrm{Cfr}$. STEDH, caso Srameck v. Austria (1984), falta de independencia que no inspira la confianza que debe exigirse en una sociedad democrática.

${ }^{59}$ STEDH, caso Erkner y Hofaver v Austria (1987), superación de plazo razonable; STEDH de 21 de abril de 2009, caso Kurty Firat v Turquía; STEDH de 21 de julio de 2009, caso Leon y Agnieszka Kania v. Polonia, paralización de medidas contaminantes; STEDH de 12 de mayo de 2009, caso Zetal v Polonia, orden de derribo.

El "plazo razonable" para decidir es "según las circunstancias y criterios consagrados por la jurisprudencia" STEDH 3097/96 caso Frigdlender v. Francia. Se vulnera cuando un tribunal administrativo de Atenas decide en 27 de octubre de 2008 un asunto iniciado en 20 de junio de 1990. STEDH de 18 de abril de 2013, caso Fergadioti-Rizaki v. Grecia.

${ }^{60}$ STEDH de 17 de octubre 2001 caso Association Ekin v. Francia; STEDH de 27 de junio de 2006, caso Saygill y Seyman v. Turquía; STEDH de 20 de octubre de 2009, caso Lombardi Vallauri v. Italia; STEDH de 21 de marzo de 2010, caso Grosaru v. Rumanía.

${ }^{61}$ Sobre la jurisprudencia anterior a la Carta de Niza y los primeros años después de ésta cfr. B. TOMÁS MALLÉN El derecho... pp. 243-264
} 
La STJCE 2007/730 de 27 de noviembre, asunto Athanasios Pitsionas/BCE relativo al acceso de los ciudadanos a los documentos puede servir de ejemplo de cómo juegan los distintos elementos de la "buena administración" en la jurisprudencia comunitaria. Se apela a ella con el recordatorio de la Sentencia del Tribunal de primera instancia de 20 de marzo de 2002, asunto ABB A Brown Boveri/ Comisión, T-31/99. Se alude al alcance de la motivación como muestra de la buena administración en STJCE de 6 de marzo de 2003 asunto Interpor/Comisión, G$41 / 2000$, con cita de otras. De paso, se recuerda que el principio de confianza legítima en la Administración, exige "concebir esperanzas fundadas" en la actuación de la Administración.

No siempre la "buena administración" aparece expresamente citada en la jurisprudencia, como ha quedado puesto de manifiesto, incluso en la del TJCE. No se alude a ella directamente como derecho fundamental, sino como principio de buena administración. Existe una inercia que todavía no se ha vencido, lo que también se comprueba en la jurisprudencia del Tribunal Supremo. Ha de descubrirse al amparo del derecho fundamental a la tutela judicial efectiva expresamente reconocido en el artículo 24 de la CE que garantiza, entre otras cosas, "un proceso sin dilaciones indebidas", o relacionada con el principio de la buena fe reconocido en el artículo 3 de la ley 30/1992 sobre régimen jurídico de las Administraciones Publicas y Procedimiento administrativo común o como falta de la motivación debida en relación con el principio constitucional de interdicción de la arbitrariedad.

Una STS de 16 de diciembre de 2010 (2010/ 9413) recuerda que una notificación correctamente practicada en el plano formal no siempre supone que se alcance la finalidad que le es propia. En esa línea la STS de 26 de noviembre de 2012 (2013/416) declara que antes de acudir a la notificación edictal o por comparecencia la Administración debe intentar la notificación en el domicilio idóneo, porque éste conste en el expediente, porque su localización resulta extraordinariamente sencilla normalmente accediendo a oficinas o registros públicos. ${ }^{62}$

Van apareciendo sentencias que expresamente se refieren al artículo 41 de la Carta europea aunque no de forma autónoma sino más bien como una confirmación del fundamento jurídico de la decisión. ${ }^{63}$ A título de ejemplo, STS de 2 de diciembre de 2011 (2012/2385) sobre confidencialidad, privacidad y seguridad; STS de 28 de septiembre de 2012 (2012/9507) sobre motivación. Expresi-

\footnotetext{
${ }^{62}$ En el mismo sentido STC 7/2006 de 13 de marzo; 2/2008 de 14 de enero y otras.

${ }^{63}$ Cfr. Las obras citadas de J. PONCE SOLÉ, B. TOMÁS MALLÉN, TORNOS MÁS.
} 
va es la STSJ de Valencia 40/2012 de 16 de enero: "Por añadidura, es evidente que se ha resentido así mismo el principio de celeridad en la actuación administrativa que tiene su formulación más clara en el derecho a una resolución dentro de un plazo razonable como parte integrante del más amplio derecho a una buena administración (artículo 41) en conexión con el artículo 2 de la ley orgánica 1/2008 de 30 de julio por el que se autoriza la ratificación por España del Tratado de Lisboa de 13 de diciembre de 2007”.

Ese reconocimiento de la "buena administración" como un derecho fundamental de la persona hace más fácil entender los esfuerzos por que se le reconozca eficacia jurídica ${ }^{64}$. No se trata de una proposición moral, un plus, que completara el cumplimiento de la legalidad. Operaría al margen del Derecho; de alguna manera se volvería a una situación histórica superada, de "moralidad administrativa" que todavía se encuentra en Hauriou: un recurso para superar las limitaciones del recurso por exceso de poder, vinculado a la ley, una autolimitación de la Administración para conseguir una razonable buena administración. Esa orientación quedaría reflejada en la explicación de la desviación de poder hoy superada. Bastará con recordar el carácter objetivo de aquella: "el ejercicio de potestades administrativas para fines distintos de los fijados por el ordenamiento jurídico" (artículo 70 LJCA). En todo caso es una cuestión jurídica, con independencia de su apreciación moral.

Sucede que en algún ordenamiento como la Constitución de Brasil de 1988 declara en su artículo 37 que la Administración Pública, en todas sus manifestaciones obedecerá, entre otros principios al de "moralidade". Y el artículo 5, inciso LXXIII reconoce la acción popular que pretenda la anulación actos lesivos a la "moralidade administrativa".

La tesis que aquí se viene defendiendo coincide con solvente doctrina brasileira que ha debido enfrentarse necesariamente con esos preceptos constitucionales. "A moralidade administrativa nao pode ser dissociadada da legalidade" 65 , del Derecho y no solo de la ley, podría entenderse (artículo 103, 1 CE). Desde esta perspectiva puede sostenerse la posibilidad de impugnar actos que vulneren principios ínsitos en el interés general. ${ }^{66}$

${ }^{64}$ En ese sentido, J. PONCE SOLÉ, Deber de...

${ }^{65}$ Cfr. MÁRCIO CAMMAROSANO, O principio constitucional da moralidade e ó exercicio da funçao administrativa, Prefácio de Celso Antonio BANDEIRA DE MELLO, Forum, Belo Horizonte, 2006, p. 102, con referencias a su maestro y Juárez Freitas entre otros.

${ }^{66}$ Cfr. ODETE MEDAUR, Direito administrativo moderno, $13^{\mathrm{a}}$ ed. Editora Revista dos Tribunais, Sao Paulo, 2009, pp. 129-130. El principio de moralidade administrativa é de difícil expressao verbal.Es pre- 
Desde una perspectiva jurídica se ha planteado la cuestión en el análisis de la potestad discrecional tal como se ha considerado tradicionalmente, de la que he discrepado de modo reiterado, entendida como la libertad de elección por la Administración de una entre varias soluciones "igualmente justas".

Desde el punto de vista del interés general, al que la Administración pública debe servir por imperativo constitucional, sólo existe una. Con razón en la jurisprudencia se ha preguntado "si en un Estado de Derecho puede admitirse la existencia a priori de algo indiferente jurídicamente" 67 . Aceptando aquel punto de vista se ha sostenido que el empleo de criterios extrajurídicos para determinar lo que es de interés general es "une condition de bonne administration pour le pouvoir éxecutif ${ }^{68}$. No interesa ahora desarrollar esa posición; bastará subrayar el esfuerzo por la consideración jurídica de la "buena administración" para el eventual control judicial, que no ha de limitarse a impedir la arbitrariedad. Quizá no sea necesario acudir al par conceptual potestad reglada-potestad discrecional. La potestad se encuentra vinculada al fin que la justifica, en el cómo, el cuándo, el cuánto. La Administración no es neutral o indiferente al interés general que la ley o el gobierno ha concretado y que ha de servir.

No se trata de que el juez substituya a la Administración, ni que ésta tenga la libertad de quien determina las políticas públicas, sino de pronunciarse en Derecho a partir de lo que conste en los autos del proceso para decidir en cada caso concreto lo que es justo, no lo que es políticamente más conveniente, para la realización del interés general. No faltan ejemplos de lo que podría dominarse la tutela del servicio al interés general ${ }^{69}$ : en materia de urbanismo, de transportes, instalación de farmacias ("lo decisivo es que la nueva instalación suponga un mejor servicio a un núcleo de población con independencia de las características, fisicas o materiales sobre las que se asienta la población $)^{70}$, justificación o motivación de la creación de una em-

ciso relacionarlo con el contexto. La compra de vehículos oficiales puede ser legal, pero resulta "inmoral" en una etapa de crisis económica. Entiendo que puede subsumirse en un principio general y en todo caso con el sometimiento de la potestad al fin que la justifica (artículo106,1 CE).

67 STS de 13 de junio de 2000 apudJ. L. MEILÁN GIL, La estructura de los contratos públicos, Iustel, 2008, pp. 231 -232 donde se expone la diferencia entre potestad discrecional y concepto jurídico indeterminado como expresiones de un proceso volitivo y de conocimiento, respectivamente. Sobre el llamado "neutralismo" de la Administración ha escrito luminosas páginas F. LÓPEZ MENUDO, La vieja cláusula "sin perjuicio de tercero" y la Administración del porvenir, Comares, Granada, 2013, pp. 58 y ss.

68 Cfr. J. PONCE SOLE, Deber... la cita es de G. ISAAC, La procédure administrative non contentieuse, LGDJ, París, 1968, tesis a la que se adhiere: pp. 128-129, 702 y ss. con el condicionamiento de los límites a que está sometida la revisión judicial.

${ }^{69}$ Cfr. J.L. MEILÁN GIL, Categorías... pp. 81-82.

${ }^{70}$ Ibid. El asunto, en que intervine profesionalmente, se refería a la instalación de farmacia en un Mu- 
presa pública, servicios esenciales y derecho de huelga, oferta económicamente más ventajosa en los contratos, opción más recomendable para la ocupación de terrenos para carreteras en materia de expropiación forzosa...

\section{La insuficiencia de la perspectiva garantista de la buena admi- nistración.}

Un gran avance se ha dado para hacer realidad la aspiración social de una buena administración con el refuerzo de los medios jurídicos expuestos. La Administración, en ese sentido, responde a la exigencia constitucional de servir los intereses generales con "objetividad", además de poder ser controlada la actuación por el sometimiento de esta a los fines que la justifican. Pero también se le exige que actúe de acuerdo con el principio de eficacia (artículo 103,1 de la CE). De una manera general se habla también de criterios de eficiencia y economía en la programación y ejecución del gasto público (artículo 31 de la CE). Criterios, que al estar previstos constitucionalmente tienen naturaleza normativa. Inciden en la actuación de la Administración, no solo en la susceptible de control judicial, sino también, por ejemplo y muy significativamente, en los procedimientos utilizados. La actuación puede adecuarse a ellos con toda corrección y, no obstante, puede quedar una razonable insatisfacción de que no se realice una "buena administración". Es el procedimiento seguido el causante de una ineficiencia.

La buena administración, no solo es un actuar, tal como se deduce del artículo 41 de la Carta de derechos fundamentales de la UE; es también estructuras y organización. Una organización administrativa adecuada para la realización de los intereses generales es síntoma de buena administración. De otra parte, una inadecuada configuración de los procedimientos de actuación puede dañar la finalidad garantista de la actuación administrativa. Salvar esos obstáculos pasa por una revisión del Derecho administrativo para que la "buena administración" sea algo más que una laudable aspiración.

La organización de la Administración Pública, salvo la relativa a los elementos fundamentales de la estructura del Estado de acuerdo con la correspondiente configuración constitucional, quedó durante muchos años fuera de la atención científica del Derecho administrativo, condicionado por una concepción estricta del método jurídico. No es del caso extenderse sobre ello y de la recuperación de su estudio dentro del Derecho administrativo, sobre lo que me referí en 1971. Incluso aunque se configure el Derecho administrativo como un sistema de garan-

nicipio de Galicia adaptando el concepto de "núcleo de población" a la realidad del asentamiento de la población. 
tías la organización de la Administración Pública no queda marginada. Esa vertiente organizativa puede ser considerada como una garantía para el particular. $\mathrm{El}$ acceso a la vía de recurso no es el todo. La razón a destiempo puede ser inútil y, lo que es peor, puede desacreditar la misma institución del recurso. La organización no es sólo una cuestión doméstica de la Administración Pública; trasciende hacia el ámbito propio del particular. La reconocida potestad doméstica de la Administración queda en entredicho en los casos de desviación de poder instados por funcionarios afectados. Y también "una deficiente disposición de las estructuras orgánicas o de los procedimientos dificulta indudablemente la actuación justa del funcionario, en su misión de aplicación de la norma”. En ese sentido llegué a afirmar que, "bajo algún aspecto el Derecho administrativo es un Derecho de organización de la convivencia". Más aún, "la organización se traduce en normas jurídicas que revelan una determinada concepción del Estado"71

Contra el desenfoque metodológico de construir el Derecho administrativo desde la óptica del control de la Administración Pública, en la que tanto ha influido la aproximación pretoriana en Francia, me pronuncié tempranamente ${ }^{72}$; ha sido calificado no hace mucho de "estrabismo del Derecho administrativo"

La vinculación, y mucho menos la identificación, de Derecho administrativo y materia contenciosa no corresponde a la realidad. Aquel no se agota en el ámbito de los recursos. La preocupación por la urgencia de lo patológico no debe impedir, podría decirse, la atención a la fisiología. El Derecho administrativo es algo más que un sistema de garantías, por muy importante que éste sea. No puede reducirse a combatir la arbitrariedad, la actuación ultra vires. Es cauce para la satisfacción de los intereses generales, que son de los ciudadanos, y justifica la misión servicial de la Administración Pública.

Esta orientación está vigorosamente subrayada en la actualidad por una importante corriente doctrinal ${ }^{74}$ y se ha puesto de manifiesto de un modo significativo en relación con el procedimiento administrativo ${ }^{75}$. No es la mera antesala del

${ }^{71}$ Cfr. MEILÁn GIL J. L., Prólogo a GALlegO ANABITARTe, A. Derecho general de organización, IEA, Madrid, 1971. A título de ejemplo cfr. GIANNINI, M. S, Diritto amministrativo, Milán, Giuffré, 1988 que dedica la parte segunda a la Teoria dell'Organizzazione.

72 Cfr. MEILAN GIL, J L, El proceso de la definición del Derecho administrativo, ENAP, Madrid, 1967.

73 S. CASSESE, "El estado presente del Derecho administrativo italiano", RAP, 183 (2010).

${ }^{74}$ Cfr. SCHMIDT-ASSMANN, E. La teoría general del Derecho administrativo como sistema. INAP-Pons, Madrid, 2003.

75 Cfr. BARNÉS, J. La transformación del procedimiento administrativo, Global Law Press, Sevilla, 2008. PONCE SOLÉ, Deber de buena administración... A. SÁNCHEZ BLANCO, "El derecho... 
contencioso, el ámbito de una justicia parcial o provisional, una garantía del particular o, para la Administración pública la ocasión de revisar sus resoluciones al resolver recursos presentados ante ella, en definitiva, el modo de preparar el acto definitivo que pueda ser impugnado ante la jurisdicción contenciosa.

La finalidad del procedimiento no se limita a procurar seguridad jurídica, evitar la arbitrariedad de la Administración, que no es poco. Los ciudadanos aspiran a que el ejercicio de sus derechos y actividades no se entorpezca por la observancia de un procedimiento inadecuadamente formulado. No debe constituir una carrera de obstáculos a salvar; es un medio para hacer realidad la "buena administración", como un deber que enlaza con el derecho al procedimiento administrativo debido.

Desde esa perspectiva ha de contemplarse el nuevo modo de administrar que se sintetiza en el e.government o Administración electrónica, en la era de Internet, símbolo de esta sociedad del conocimiento y la información: nuevos modos de notificación, de identificación, de archivo y también procura de la seguridad jurídica, la neutralidad tecnológica, respeto al derecho de protección de datos de carácter personal. Toda una revolución que precisa una cultura democrática de manera que la Administración no se convierta en el nuevo Leviatán y, a veces, ocurre.

A esa preocupación, no meramente garantista, responden los diversos programas de reforma administrativa. Preocupación paradigmática como intento de renovación del "Estado administrativo" anterior a la CE de 1978. A eso obedeció la creación de la Secretaría General Técnica de la Presidencia del Gobierno, cuyo primer titular, el profesor Lopez Rodó impulsó reformas legales sobre procedimiento administrativo, funcionarios -incluida su selección y formación-, organismos autónomos y empresas públicas, generalización de órganos on line y staff $f^{76}$. Para lo que aquí se está tratando convendrá recordar que en la ley de Procedimiento de 17 de julio de 1958 se decía que "la actuación administrativa se desarrollará con arreglo a normas de economía, celeridad y eficacia y se hablaba de tareas de normalización y racionalización (artículo 29) que se desarrollaban en artículos posteriores. ${ }^{77}$

El último intento es el informe CORA (Comisión para la reforma de las Administraciones Públicas, 2013) que se inserta en el conjunto de reformas em-

\footnotetext{
${ }^{76}$ Cfr. L. LÓPEZ RODÓ, La Administración Pública y las transformaciones socioeconómicas, ENAP, Madrid,

77 Cfr. A. SÁNCHEZ BLANCO, "El derecho... cit.
} 1963. 
prendidas por el Gobierno con ocasión de la crisis financiera y económica. No es del caso analizar su contenido, sino tomar conciencia de lo que se viene sosteniendo. En su preámbulo se manifiesta que "se puede afirmar sin reservas que España tiene una buena administración". Pero se reconoce que "también existen ineficiencias y redundancias competenciales que deben corregirse". Quizá la más relevante novedad proviene de la configuración constitucional del Estado, como Estado compuesto o autonómico. De ahí la relevancia que se da a las duplicidades administrativas, tanto orgánicas como de competencias. Por supuesto perviven cuestiones tradicionales sobre simplificación administrativa, o Administración institucional, obviamente replanteadas como sucede con la gestión de servicios y medios comunes.

\section{Eficacia jurídica de principios programáticos.}

Una aplicación de la orientación expuesta del Derecho administrativo es el reconocimiento de la efectiva operatividad de principios que se contienen en leyes con carácter formalmente programáticos. Podría decirse también que supone la integración de principios de la Ciencia de la Administración en el ordenamiento jurídico. Es el caso de eficacia, eficiencia, economía, proporcionalidad, transparencia, accesibilidad, simplicidad, que se erigen en criterios de actuación en diversos sectores $^{78}$. Un ejemplo relativamente reciente valdrá para esta exposición.

La ley 2/2012 de 27 de abril de estabilidad presupuestaria y sostenibilidad financiera, consecuencia de la modificación del artículo 135 de la CE por exigencias de la UE, contiene principios de estabilidad presupuestaria, sostenibilidad financiera, transparencia, eficiencia en la asignación y utilización de los recursos públicos, además de responsabilidad y lealtad constitucional. Obligan a las Administraciones con efectos jurídicos reconocidos en la ley, no solo porque pautan la actuación de la Administración, sino también por las medidas que pueden adoptarse en caso de incumplimiento: necesidad de autorización, e incluso su negación, para las operaciones de endeudamiento de las Comunidades Autónomas o Corporaciones locales, pudiendo llegar a la disolución de los órganos de gobierno de estas últimas.

Uno de los retos del Derecho administrativo actual es, precisamente, hacer operativos para la revisión judicial muchos de esos principios que vinculan a la potestad de la Administración en su actuación servicial de los intereses generales.

${ }^{78}$ En materia medioambiental están consagrados el principio de precaución, la actuación de acuerdo al mejor conocimiento científico posible que recoge la ley 21/2013 de 9 de diciembre de evaluación ambiental. 
Si una ley de dependencia, para hacer frente a una necesidad creciente por, entre otras causas, el aumento de la edad de vida de los ciudadanos, dice que la atención sea integral, su desarrollo reglamentario no puede ignorarlo.

No es una tarea fácil, pero ha de intentarse sin escudarse en una superada concepción de la discrecionalidad y en la impotencia judicial para sustituir la decisión de la Administración, colocándose en el lugar del juez.

El principio de eficiencia obliga a optimizar los recursos públicos, que provienen de los ciudadanos, de lo que habla el artículo 31 de la CE citado anteriormente. Quizá sea más propio que el de eficacia que se recoge en el citado artículo 103,1 de la CE, y reconoce el TC (STC 22/1984) como pauta de actuación de la Administración. Principio que ha de operar "en la resolución de los conflictos sociales y la satisfacción de las necesidades de la colectividad (STC 178/1989). Afecta al buen gobierno, al diseño de las políticas públicas, pero también a la buena administración. Ha de tenerse en cuenta, por ejemplo, para decidir la "oferta económicamente más ventajosa" en los contratos del sector público cuya valoración no queda reducida al momento en que se realiza la adjudicación del contrato ${ }^{79}$. Tiene incidencia en el campo, especialmente sensible, de las prestaciones y servicios sociales, y plantea la cuestión de la participación de la sociedad en lo que es actividad de la Administración.

Participación y democracia van unidas, se corresponden esencialmente. De democracia participativa hablaba la non nata Constitución europea. Como derecho fundamental se reconoce en la CE (artículo 23,1) el que tienen los ciudadanos a participar en los asuntos públicos, aunque no todo derecho de participación tiene ese carácter (ATC 942/85 de 18 de diciembre). Ello permite concluir, desde una interpretación positiva, la existencia de derechos de participación en ámbitos propios de la Administración, distintos de la participación política. De hecho, la participación de la sociedad en la realización de los intereses generales que la Administración sirve ha crecido por imperativos democráticos y ha influido en la construcción misma del Derecho administrativo.

Existen funciones en que esa participación es clara: en los procedimientos administrativos, en la programación y planificación, en la elaboración de las normas en que se concretan, en definitiva, las políticas públicas. Esa participación se reclama en ámbitos como medio ambiente, por influjo del Derecho comunitario, urbanismo, aspectos de la Administración local, entre otros.

${ }^{79}$ Cfr. J. PERNAS, Contratación pública ... con prólogo de J.L. MEILÁN. 
La participación de la sociedad se ha revelado de gran importancia en relación con las prestaciones y servicios sociales, reclamados para una calidad de vida exigible en esta altura de los tiempos, en cuya materia es preciso un replanteamiento doctrinal.

Es un dato reconocido la voluntad de los revolucionarios franceses de acabar con los estamentos y organismos intermedios existentes en el Antiguo Régimen. El nuevo Estado no asumió actividades educativas y asistenciales, en gran mayoría desarrolladas en Europa por la Iglesia. Un paso importante en la evolución de la historia ha sido la asunción por el Estado de responsabilidad en estas y análogas materias, reconocidas en prestaciones que han dado lugar al "Estado de bienestar" ${ }^{\prime 0}$. Las dificultades por las que atraviesa son, en buena parte, consecuencia de su éxito. Un número creciente de personas y un ámbito mayor de cobertura presionan contra la carga financiera que supone para el Estado.

Hay una imbricación recíproca de acción estatal y vida social. El Estado, al asumir la obligación de hacer real y efectivo el bienestar, es un Estado garante, lo que conlleva la realización directa de prestaciones, pero también el reconocimiento de que desde la sociedad se contribuya libremente a esa realización. ${ }^{81}$ Existe, como ha dicho el Tribunal Constitucional una "interpenetración entre Estado y sociedad", para concluir lapidariamente: "La configuración del Estado como social y de Derecho viene así a culminar una evolución en la que la consecución de los fines de interés general no es absorbida por el Estado, sino que se armoniza en una acción mutua Estado-sociedad".

La crisis actual ha puesto en evidencia esa necesidad. No se trata de minorar las conquistas sociales, sino de garantizar su mantenimiento y mejora. Es preciso para ello superar una concepción ideológica sustentadora del monopolio del Estado en la materia, en cuya base sigue existiendo la contraposición hegeliana entre lo público, caracterizado por la razón, y lo privado o particular, dominado por

80 No es cuestión de desarrollar lo que corresponde al Estado social, la aportación de E. FORSTHOFF, Rechstfragen der leistenden Verwaltung Stuttgart, 1950; Tratado de Derecho administrativo, trad. Española, IEP, Madrid, 1958; Problemas actuales del Estado social de Derecho en Alemania, ENAP, 1966. H.J. WOLFF, Verwaltungsrecht, I, 5ª ed. Munich y Berlín, 1963 pp. 45-46. Sobre la actividad empresarial del Estado J.L. MEILÁN, Empresas públicas y turismo, ENAP, Madrid, 1967 con bibliografía española y europea. Una magnífica aproximación desde la perspectiva aquí considerada en J.M ${ }^{\mathrm{a}}$ RODRÍGUEZ DE SANTIAGO, La administración del Estado social, Marcial Pons, Madrid, 2007. Sobre una cuestión que se ha planteado con especial relevancia por la crisis económica cfr. J.PONCE SOLÉ, El derecho y la (ir) reversibilidad limitada de los derechos sociales de los ciudadanos, INAP, Madrid, 2013.

${ }^{81}$ Cfr. J.L. MEILÁN GIL, "Sobre la revisión del Derecho administrativo, FIDA, Santo Domingo, 2012. 
el beneficio. Habría que hablar de sistema: de salud, de asistencia social y dependencia, de educación. Lo definitivo es que el sistema sea universal y de la mejor calidad. Es lo que el Estado ha de garantizar, sin excluir la participación de la sociedad; más aún puede necesitar de ella para cumplir su función.

La participación de la sociedad en estos ámbitos se constata en la existencia de numerosas organizaciones sin fines de lucro, bajo formas jurídicas distintas, que se sitúan, para decirlo de un modo gráfico, entre el Estado y el mercado, lo que se ha denominado el tercer sector: promovidas por la Iglesia, Fundaciones, Corporaciones y, en general, organizaciones no gubernamentales, fruto de la libertad de asociación, y que responden al principio de solidaridad.

En esa línea se encuentra la ley 5/2011 de Economía social, que se hace eco de iniciativas comunitarias. Constituye un marco jurídico común para las actividades desarrolladas en el ámbito privado con independencia respecto de los poderes públicos bajo principios del interés general económico o social, o de ambos (artículo 2), de promoción de la solidaridad que favorezca, entre otros objetivos, la cohesión social y la inserción de personas con riesgo de exclusión social.

Una apelación a ellas y a las familias, se realiza en la ley sobre dependencia, cuya programada cobertura económica es insuficiente y se ha reducido como consecuencia de ajustes presupuestarios. Las cifras de las prestaciones sociales desde la vertiente de esas organizaciones revelan dramáticamente su justificación en la actual coyuntura de crisis y elevado número de parados.

\section{El Defensor del Pueblo y la mala administración.}

Existen organismos que, sin formar parte de ninguno de los poderes del Estado tienen que ver con prácticas y actuaciones que suponen una mala administración e inversamente, por tanto, con la buena administración. Su gran fuerza proviene de su independencia, como muestra de un modo paradigmático la historia del Ombudsman sueco, que ha sido la referencia de los demás que con diferentes nombres se han creado en otros países. En España se introdujo en el artículo 54 de la CE, con el nombre de Defensor del Pueblo, "como alto comisionado de las Cortes Generales" que lo nombra por amplio consenso y con quienes se relaciona ${ }^{82}$.

${ }^{82}$ Esa definición proviene de Gran Bretaña donde había sido embajador el ponente constitucional que la sugirió. 
Con el nombre de Defensor del pueblo europeo consta en el artículo 228 del Tratado de funcionamiento de la Unión Europea y es nombrado por el Parlamento europeo. La experiencia acumulada por entes de la misma naturaleza manifiesta una posición equilibrada en cuanto a su función que se refiere a casos de mala administración por parte de las instituciones, órganos u organismos de la UE, con exclusión de los Tribunales de Justicia en el ejercicio de sus funciones jurisdiccionales. La explicación del Ombudsman sueco tiene que ver en su inicio con la inexistencia de un sistema contencioso-administrativo y, por ello, de difícil trasplante a los países que lo tienen y en todo caso no conciliable con la independencia de los jueces. Así se comprende que el Defensor del Pueblo pueda conocer de las quejas de cualquier ciudadano europeo salvo de que los hechos alegados sean o hayan sido objeto de un procedimiento jurisdiccional. El Defensor las pone en conocimiento de la institución, órgano u organismo afectado, que tiene un plazo de tres meses para responder y aquel enviará informe correspondiente al Parlamento ${ }^{83}$

En el caso español la función principal del Defensor del Pueblo es la defensa de las libertades y derechos fundamentales reconocidos en la Constitución "a cuyo efecto podrá supervisar la actuación de la Administración, dando cuenta a las Cortes Generales". La ley 3/1981 de 6 de abril que regula la institución concreta que de oficio o a petición de parte puede llevar a cabo cualquier investigación conducente al esclarecimiento de los actos y resoluciones de la Administración y de sus agentes en relación con los ciudadanos, a la luz de lo dispuesto en el artículo 103.1 de la CE y el respeto de los derechos fundamentales.

De acuerdo con ello podría interpretarse que la investigación puede referirse a la comprobación de si la Administración actúa sin objetividad, sin acuerdo con principios de eficacia, sin sometimiento pleno a la ley y al Derecho, cometido en último término de los Tribunales como dice el artículo 106 o solo en cuanto se refiera al no respeto de los derechos fundamentales.

El reconocimiento de la buena administración como derecho fundamental, tal como se realiza en la Carta europea, proporciona fundamento para justificar el alcance de la competencia del Defensor aunque se limite a realizar advertencias, recomendaciones y sugerencias, además de informar anualmente al Parlamento. En ese sentido puede sugerir al órgano legislativo o a la Administración realizar modificaciones cuando llegue al convencimiento de que el empleo riguroso de la norma pueda provocar situaciones injustas o perjudiciales para los administrados.

\footnotetext{
${ }^{83}$ Cfr. B.TOMÁS MALLÉN, El Derecho... pp. 221 y ss.
} 
Cuando entienda que una ley vulnere un derecho fundamental puede interponer un recurso de inconstitucionalidad. Esa facultad tiene un especial significado e importancia dado que la legitimación para interponerlo queda de hecho limitada a dos grandes partidos que pueden estar de acuerdo, por razones políticas, en no interponerlo.

\section{Actualidad de la transparencia para la buena administración.}

El artículo 103 de la CE establece que la Administración Pública actuará con objetividad en su servicio a los intereses generales. Es más que la interdicción de la arbitrariedad. Responde a la obligación de "mantener los servicios públicos a cubierto de toda colisión entre intereses particulares e intereses generales" (STC 77/1985 de 27 de junio). Con toda lógica se acompaña con la transparencia (ley de organización y funcionamiento de la Administración General del Estado, artículo 3, 2, g), relacionada con la necesidad de rendir cuentas de la gestión ante los ciudadanos.

La transparencia va más allá de la obligación de motivar la actuación, y de la información y publicidad, aunque las englobe. Se ha dicho que es el derecho de los ciudadanos de conocer y "entender" la actividad administrativa. ${ }^{84}$ Un conocimiento o entendimiento que se adquiera de un modo fácil, sin que sea el resultado de un esfuerzo que requiera la especialización del ciudadano interesado. No es mera información, sino información de tal calidad que cumpla con las condiciones que acaban de exponerse. Un exceso de información puede incluso dificultar la transparencia. La información, que desempeña un papel fundamental en la Administración Pública de un sistema democrático, puede hacer opaca la actuación de aquella si se presenta de un modo sesgado o, todavía peor, cuando es manipulada desde instrumentos de opinión pública controlados por la Administración.

La transparencia hace más difícil que aparezca ese elemento corrosivo de la democracia que es la corrupción. De ahí la importancia que se le está dando en los ordenamientos jurídicos de una manera general y frontal superando regulaciones sectoriales. Es lo que pretende la ley 19/2013 de 9 de diciembre de Transparencia, Acceso a la Informacion Pública y Buen Gobierno, en cuya elaboración se ofreció una audiencia a los ciudadanos para que pudieran remitir sugerencias. Existen referencias en determinadas materias: contratos públicos, sub-

${ }^{84}$ Cfr. M. R. SPASIANO, "Transparency and quality of administrative action", en M.PILADE CHITI (ed.) General Principles of administrative action, Bolonia University Press, 2006. 
venciones, presupuestos, actividades de altos cargos, acceso a los expedientes en los correspondientes procedimientos administrativos. Con esa ley se pretende generalizar ampliar y profundizar la transparencia, así como concretar las consecuencias jurídicas de su no observancia.

Desde este punto de vista se lleva a cabo el encuentro enunciado anteriormente entre Ciencia de la Administración y Derecho administrativo. "En lo que respeta al buen gobierno la Ley supone un avance de extraordinaria importancia. Principios meramente programáticos y sin fuerza jurídica se incorporan a una norma con rango de ley y pasan a informar la interpretación y aplicación de un régimen sancionador al que se encuentran sujetos todos los responsables públicos", que "por las funciones que realizan deben ser un modelo de ejemplaridad en su conducta". En ese sentido se incorporan a la ley "principios éticos", así denominados, que adquieren la virtualidad de preceptos jurídicos.

La exposición de motivos, subraya con cierta solemnidad, el propósito último de la ley: "La transparencia, el acceso a la información pública y las normas de buen gobierno deben ser los ejes fundamentales de toda acción política. Sólo cuando la acción de los responsables públicos se somete a escrutinio, cuando los ciudadanos pueden conocer cómo se toman las decisiones que les afectan, cómo se manejan los fondos públicos o bajo qué criterios actúan nuestras instituciones podremos hablar del inicio de un proceso en el que los poderes públicos comienzan a responder a una sociedad que es crítica, exigente y que demanda participación de los poderes públicos".

El ámbito de la ley rebasa el de las Administraciones Públicas en sentido orgánico, que incluye a Universidades, y abarca a poderes públicos como el Congreso de los Diputados y el Senado, y el Consejo General del Poder Judicial e instituciones análogas aunque "en relación con sus actividades sujetas al Derecho administrativo" $"$. Una vez más se constata la validez de la orientación ratione materiae que he venido defendiendo desde el principio. Bien es verdad que se ha ampliado el ámbito de la ley más allá de esa concepción de lo administrativo: partidos políticos, organizaciones sindicales y empresariales, entidades privadas que perciban en el período de un año ayudas o subvenciones públicas en cantidades significativas ${ }^{86}$.

\footnotetext{
${ }^{85}$ Corporaciones de Derecho público, Fundaciones, Casa del Rey.

${ }^{86}$ Superiores a 100.000 euros o que el 40\% del total de sus ingresos sea igual o superior a 5.000 euros.
} 
Están obligadas a publicar "de forma periódica y actualizada la información cuyo conocimiento sea relevante para garantizar la transparencia de su actividad relacionada con el funcionamiento y control de la actuación pública". El Portal de la Transparencia dependiente de la Presidencia del Gobierno pretende hacer fácil el acceso de los ciudadanos a la información. Las Administraciones Públicas han de publicar los planes y programas con el suficiente detalle que permita la evaluación de su cumplimiento.

Contra toda resolución expresa o presunta en materia de acceso a la información se podrá interponer una reclamación ante el Consejo de transparencia y buen gobierno con carácter potestativo previo al contencioso-administrativo. La resolución, calificada de presunta por dejar transcurrir el plazo de tres meses sin resolver expresamente, evidencia el carácter negativo del silencio al entender desestimada la petición del ciudadano.

Capítulo importante para comprobar la efectividad de tan saludables propósitos, es el concerniente a infracciones y sanciones. Se contienen en el título II de la ley que se refiere al buen gobierno y afecta solo a los miembros del Gobierno y altos cargos. Entre las primeras cobran especial relevancia las relativas a materia de gestión económico-presupuestaria, dada la importancia que ha cobrado la estabilidad financiera y los ajustes a que ha obligado su desvío por exigencias comunitarias. Como muy graves se tipifican los compromisos de gastos, reconocimiento de obligaciones y ordenación de pagos sin crédito suficiente para realizarlos o contraviniendo disposiciones de la legislación presupuestaria. Entre las sanciones figuran la destitución de cargos públicos o inhabilitación.

\section{EPÍLOGO SOBRE ÉTICA Y ADMINISTRACIÓN}

El Derecho administrativo, me gusta decir, es un Derecho de realización y suscribo la determinación constitucional de que la Administración sirve los intereses generales con eficacia, pero con sometimiento pleno al Derecho, sin que haya de entenderse éste como un positivismo que excluya principios, en una contraposición infranqueable entre el sein y el sollen.

No parece necesario extenderse en la relación y diferencia entre Ética y Derecho. Para una concepción positivista del Derecho resulta difícil explicar expresiones - preceptos jurídicos- en la Constitución o en las leyes que aluden a la moral o a la ética: el derecho al honor, la objeción de conciencia, el derecho de los padres a que sus hijos reciban la formación religiosa y moral que esté de acuerdo con sus propias convicciones... Hunden sus raíces más allá del Derecho positivo, como sucede con la dignidad de la persona humana," fundamento del orden político y de la paz social" (artículo 10,1 de la CE). Los derechos fundamen- 
tales reconocidos, no creados, por los ordenamientos positivos, se corresponden con los derechos humanos, objeto de Declaración universal, que han de ser presentados como "el lenguaje común y el sustrato ético de las relaciones internacionales" $" 87$.

No resulta sorprendente que en la propia Constitución se aluda expresamente a la ética o a la moralidad de la actuación en el ámbito de la Administración Pública como ocurre en la Constitución de Brasil anteriormente referida. La Convención interamericana contra la corrupción, señala desde el preámbulo que esa actuación negativa va "contra la sociedad, el orden moral y la justicia"... La Declaración del milenio de NU del 2000 afirma de un modo categórico que la corrupción puede contemplarse "como un sistema de mala administración y una mala gestión".

En otras ocasiones esa finalidad se concreta en modalidades del denominado soft law, Códigos de Conducta o de Buenas prácticas con los que se orienta el comportamiento de autoridades públicas y se practica también en el ámbito privado. Ha surgido de un modo natural en procesos formales de integración, como la Unión Europea, o informales como sucede en la globalización. ${ }^{88}$

La ética no se refiere propiamente a la Administración Pública como una abstracción, sino a la actuación de las personas que la integran, como se dijo al principio y a las personas que se relacionan con ella. Aunque la realización del Derecho que concierne a la Administración no agote el alcance de la dimensión ética de la actuación de sus autores, en gran medida el comportamiento conforme a Derecho es síntoma de comportamiento ético. La desviación de poder, en el mayor número de los casos, supone una conducta éticamente reprobable, aunque técnicamente no haya sido así calificada en un proceso. Algo parecido podría decirse de la arbitrariedad, motivación ausente o sesgada.

La corrupción, se corresponde con actuaciones de esa naturaleza, sean puniblemente castigadas o toleradas o silenciadas. En ella se da un conflicto de intereses, en cuanto un funcionario público que está vinculado por un deber de servicio al interés general lo subordina a un interés particular, suyo o de otra persona física o jurídica. Los contratos o el urbanismo son campos desgraciadamente típicos para actuaciones jurídica y éticamente reprobables.

${ }^{87}$ Discurso de Benedicto XVI ante la Asamblea de Naciones Unidas, 18 de abril de 2008.

88 Cfr. J. L MEILÁN GIL, "Sobre la revisión... ; Una aproximación al Derecho administrativo global, Editorial Derecho Global, Sevilla, 2011. 
El comportamiento ético, en el sentido que aquí se viene manejando, puede ser favorecido o perjudicado por el comportamiento que se lleva a cabo en el nivel propiamente político o de gobierno. Los procedimientos no reglados para el acceso a la función pública no favorecen el comportamiento ético. Los cambios en la función pública según los que se producen en el gobierno, hace posible la consideración del puesto como un botín, desde el que beneficiar al partido político que propició el nombramiento. Informaciones privilegiadas a la hora de concursos, por ejemplo, pueden ser una contraprestación o el espurio entendimiento de la fidelidad partidaria, aunque no se procuren beneficios personales directos.

En términos positivos, habría que concluir que un sistema de selección de los funcionarios basado en el mérito, la capacidad, la transparencia y seguridad jurídica, es una condición aconsejable para asegurar comportamientos éticos y, por supuesto, la existencia de garantías para la imparcialidad en el ejercicio de sus funciones (artículo 103,1, CE).

El contexto social en el que se desenvuelve la actividad de la Administración pública puede incidir también positiva o negativamente en el comportamiento ético de sus servidores. Existe consenso en considerar que en el meollo de la crisis financiera y económica actual se detecta un comportamiento reprobable desde el punto de vista ético. Esas conductas en el sector privado constituyen un mal ejemplo para la Administración Pública y sus agentes. El impacto negativo será menos probable si, como dice la Convención interamericana contra la corrupción, se han adoptado medidas que tengan en cuenta "la relación entre una remuneración equitativa y la probidad en el servicio".

La clave última del cumplimiento de la misión de servicio público de los funcionarios radica en convicciones éticas que tienen su explicación, más allá del Derecho y su cuidada observancia. Volvemos así a ponderaciones clásicas, trátese del imperativo ético o, más inteligible para una antropología realista, de la virtud que hace al hombre feliz, contento con lo que hace y por qué y para qué lo hace, consciente de la lealtad a una misión que vale la pena desarrollar. 